\title{
A ACESSIBILIDADE DIGITAL NO ENSINO SUPERIOR A DISTÂNCIA: ESTUDOS PRELIMINARES
}

\author{
Adriana Aparecida de Lima Terçariol', Elisangela Aparecida Bulla Ikeshoji ${ }^{2}$ \\ ${ }^{1}$ Universidade do Oeste Paulista - UNOESTE, Mestrado em Educação, Presidente Prudente, SP. ${ }^{2}$ Instituto Federal de \\ Educação, Ciência e Tecnologia de São Paulo, Câmpus Birigui, SP. E-mail: adrianalima@unoeste.br; \\ elisangela.bulla@gmail.com.br
}

\section{RESUMO}

O presente estudo constitui-se como parte da pesquisa "Acessibilidade Digital nos Cursos a Distância: Construindo Ambientes Virtuais Inclusivos no Ensino Superior", vinculado ao Programa de Mestrado em Educação da Universidade do Oeste Paulista - UNOESTE/SP, na linha de pesquisa "Formação e Prática Pedagógica do Profissional Docente". Nesse sentido, este estudo foi realizado a partir de um levantamento bibliográfico sistemático das publicações científicas, na base de dados do Scielo (Scientific Eletronic Library Online), produzidas nos últimos sete anos, de 2010 a 2016. Como resultado foi possível perceber que a acessibilidade digital contemplada em cursos a distância na Educação Superior é amparada por legislações aplicáveis. No entanto, a acessibilidade digital precisa ser compreendida com elemento que vai além das atividades e planejamentos das interfaces do AVA, pois a tecnologia deve ser entendida, enquanto instrumento facilitador do processo de ensino e aprendizagem, devendo ser utilizada, em favor das necessidades dos estudantes.

Palavras-chave: Acessibilidade Digital, Educação a Distância, Ensino Superior.

\section{DIGITAL ACCESSIBILITY IN HIGHER EDUCATION BY DISTANCE LEARNING CURSES: PRELIMINARY STUDIES}

\begin{abstract}
This article was developed as part of the research "Digital Accessibility in Distance Learning Courses: Building Inclusive Virtual Environments at University", linked to the Master of Education Program at the UNOESTE University, line of research "Training Educational and Professional Teaching Practice ". This study was made from a systematic literature research based on scientific publications in the Scielo database (Scientific Electronic Library Online) produced between 2010 and 2016. As a result was possible to verify that digital accessibility in distance learning courses at universities is supported by government laws. However, digital accessibility needs to be understood with element that goes beyond the activities and planning of AVA interfaces, because the technology should be understood as facilitator of teaching and learning process and it should be used to meet student needs.
\end{abstract}

Keywords: Digital Accessibility, Distance Education, Higher Education. 


\section{INTRODUÇÃO}

As demandas emergentes da sociedade contemporânea evidenciam a necessidade de ampliação de oferta de formação em nível superior nas diversas áreas do conhecimento, fato esse que vem impulsionando as Universidades e os centros de formação (Institutos de Ensino Superior - IES) a reconhecerem na Educação a Distância (EaD) uma oportunidade para a ampliação de vagas para cursos de graduação e pós-graduação. Nos dias atuais inúmeras são as legislações que apoiam as IES a estenderem sua atuação também nesta modalidade. No entanto, muito ainda precisamos avançar no planejamento e desenvolvimento de cursos a distância no ensino superior, de modo que realmente sejam acessíveis a qualquer pessoa, independente de suas características físicas, sociais e intelectuais.

No caso da EaD que é mediada com recursos tecnológicos é importante compreendermos que estes são fundamentais para promoção de uma educação inclusiva. Em se tratando, especialmente, da convivência em um ambiente virtual de aprendizagem, por um lado, as pessoas com deficiência ou com necessidades especiais adquirem a possibilidade de estar numa plataforma ou espaço no qual podem interagir em condições de igualdade com as pessoas "sem deficiência" ou "ditas normais", porém, por outro, torna-se de extrema importância que a IES estejam também atentas e reconheçam às novas necessidades que surgem diante das inúmeras diretrizes legais que defendem que a Educação em todos os níveis de ensino seja inclusiva, preocupando-se com a acessibilidade desde o processo seletivo, ao AVA, às ferramentas de interação e comunicação via Web, ao acesso aos conteúdos distribuídos nos livros didáticos e nas diversas mídias integradas ao curso, bem como com todos os outros detalhes que um curso de qualidade a distância exige.

Portanto, o objetivo desta pesquisa foi investigar como a acessibilidade digital pode ser contemplada em cursos a distância na Educação Superior, visando à construção de ambientes virtuais de aprendizagem inclusivos, independente das necessidades especiais dos estudantes. A seguir apresentamos a metodologia adotada para a revisão sistemática da literatura realizada no âmbito desta investigação e na sequência discutimos a partir de alguns eixos temáticos as descobertas evidenciadas neste percurso.

\section{METODOLOGIA}

Este estudo é fruto de levantamento bibliográfico sistemático. A escolha por este tipo de pesquisa se deu em função de possibilitar o contato com os conhecimentos já produzidos na área, no caso, sobre "EaD e Acessibilidade Digital", bem como a identificação das ideias relevantes sobre o tema. De acordo com Moura, Ferreira e Paine (1998, p. 35) "a escolha de um tema de pesquisa exige que se tenha familiaridade com o que já foi pesquisado sobre aquele tema".

Sendo assim, essa aproximação mais estreita com o tema, considerando os estudos existentes, ocorreu no contato e busca com as publicações disponibilizadas na base de dados do Scielo (Scientific Eletronic Library Online). A escolha por essas bases de dados se justifica por estarem disponíveis aos usuários, de forma online, possibilitando o acesso a textos completos que abrangem várias áreas do conhecimento.

Como critério de seleção dos trabalhos encontrados na área, optou-se, por focar o levantamento de publicações científicas, produzidas nos últimos sete anos, de 2010 a 2016 . A partir desse recorte, os descritores utilizados foram: "Acessibilidade Digital" - 9 artigos disponibilizados; "Acessibilidade Educação Superior" - 7 artigos disponibilizados; "EaD e Acessibilidade" - 4 artigos disponibilizados. Na sequência, todos os artigos disponibilizados foram lidos na íntegra, mas os que puderam contribuir com a pesquisa e realizados os fichamentos para que fosse possível identificar as ideias principais, são: "Acessibilidade Digital" - 1 artigo disponibilizados; "Acessibilidade Educação Superior" - 4 artigos; "EaD e Acessibilidade" - 1 artigo. Essas ideias, portanto, contribuíram para nortear as reflexões nos itens apresentados a seguir. 


\section{EDUCAÇÃO INCLUSIVA PAUTADA EM POLÍTICAS PÚBLICAS}

A Acessibilidade pode ser entendida como a condição facilitadora, às pessoas com deficiências ou com mobilidade reduzida, para utilização com segurança e autonomia dos espaços, mobiliários e equipamentos urbanos, das edificações, dos transportes, dos meios de comunicação e informação (BRASIL, 2004; IPHAN, 2003; BRASIL 2000).

E para que os bens culturais imóveis estejam disponíveis a todos sem distinção, faz-se necessário eliminar as barreiras, esta entendida como: obstáculo, atitude ou comportamento que limita ou impede a participação social e o exercício dos direitos à acessibilidade. Em se tratando da modalidade de Educação a Distância, as barreiras nas comunicações e na informação relacionamse aos aspectos em que dificulta ou impossibilita a expressão ou o recebimento de mensagens e de informações, por meio dos sistemas de tecnologias (BRASIL, 2015).

Sendo a comunicação,

forma de interação dos cidadãos que abrange, entre outras opções, as línguas, inclusive a Língua Brasileira de Sinais (Libras), a visualização de textos, o Braille, o sistema de sinalização ou de comunicação tátil, os caracteres ampliados, os dispositivos multimídia, assim como a linguagem simples, escrita e oral, os sistemas auditivos e os meios de voz digitalizados e os modos, meios e formatos aumentativos e alternativos de comunicação, incluindo as tecnologias da informação e das comunicações. (BRASIL, 2015).

Essas formas de comunicação possibilitam o acesso aos bens culturais, principalmente, quando se trata de pessoas com necessidades especiais.

O Decreto no 5.296/2004 estabelece normas gerais e critérios básicos para a promoção da acessibilidade das pessoas com deficiência ou com mobilidade reduzida. De acordo com a limitação ou a incapacidade para desempenho de atividades, enquadra-se nas categorias as pessoas com deficiência: física, auditiva, visual, intelectual e múltipla. E a pessoa que não se enquadra nas categorias de deficiência, mas possui mobilidade reduzida seja de coordenação motora e percepção ou de flexibilidade (BRASIL, 2004).

Nesta mesma perspectiva, o referido Decreto trata que os projetos arquitetônicos e urbanísticos devem atender os princípios da universalidade para promoverem acessibilidade. 0 poder público deve promover a inclusão de conteúdos temáticos nas diretrizes curriculares da educação profissional e tecnológica, assim como dos cursos superiores de Engenharia, Arquitetura e correlatos. De maneira afirmativa, os estabelecimentos de ensino, segundo item II do artigo 24 "coloca à disposição de professores, estudantes, servidores e empregados portadores de deficiência ou com mobilidade reduzida ajudas técnicas que permitam o acesso às atividades escolares e administrativas em igualdade de condições com as demais pessoas" (BRASIL, 2004).

Diante do exposto, percebe-se que é necessário refletir sobre o planejamento das ações nos espaços educativos, visto que as políticas públicas enquanto instrumentos para viabilizar a educação inclusiva. Fica evidente, portanto, essa questão a partir de 2008 com o Plano Nacional de Educação Especial na Perspectiva da Educação Inclusiva.

Para atuar na educação especial, o professor deve ter como base da sua formação, inicial e continuada, conhecimentos gerais para o exercício da docência e conhecimentos específicos da área. Essa formação possibilita a sua atuação no atendimento educacional especializado e deve aprofundar o caráter interativo e interdisciplinar da atuação nas salas comuns do ensino regular, nas salas de recursos, nos centros de atendimento educacional especializado, nos núcleos de acessibilidade das instituições de 
educação superior, nas classes hospitalares e nos ambientes domiciliares, para a oferta dos serviços e recursos de educação especial. (BRASIL, 2007).

Para Mantoan (2011) os movimentos contrários à discriminação não favoreciam a inclusão, pois diferenciada o atendimento dos estudantes dos ambientes comuns de escolarização, em classes e escolas especiais, somente após a política nacional de educação especial, em 2008, na perspectiva da educação inclusiva é que trouxe novas concepções à atuação da educação especial, em nossos sistemas de ensino. O que não significa afirmar que tais aspectos tenham sido apropriados pelos atores educacionais e desenvolvidas no espaço escolar, segundo uma concepção de não exclusão.

Nas instituições federais de ensino, segundo o Decreto $n^{\circ} 7.611 / 2011$ é dever do Estado dar apoio técnico para "estruturação de núcleos de acessibilidade nas instituições federais de educação superior". Assim como esses núcleos visam "eliminar barreiras físicas, de comunicação e de informação que restringem a participação e o desenvolvimento acadêmico e social de estudantes com deficiência." (BRASIL, 2011).

Porém, ainda que as condições não sejam adequadas para proporcionar a eliminação de barreiras, um aspecto fundamental a ser vencido é a sociedade compreender que as barreiras devem ser derrubadas em cada contexto, segundo o olhar de cada ser humano para com o outro.

\section{ACESSIBILIDADE DIGITAL EM EAD NA EDUCAÇÃO SUPERIOR}

A acessibilidade digital segundo Santarosa, Conforto e Basso (2012, p. 455) deve ser concebida como "uma interface projetada a partir de princípios de usabilidade e de acessibilidade deve permitir colocar o foco no processo de mediação entre pares e não na apropriação da tecnologia computacional." Sendo a tecnologia um instrumento utilizado em favor das necessidades dos estudantes e todos os profissionais envolvidos.

Corrobora Flor et al. (2015) quando destaca que os profissionais devem voltar seus esforços para elaborar os conteúdos orientados às características e às necessidades dos estudantes. Como, por exemplo, compreender a diferença que os surdos apresentam em relação aos estudantes ouvintes, pois "sem tal compreensão, a tendência é que os profissionais ouvintes continuem a desenvolver conteúdos fundamentados em sua cultura e percepção da realidade [...]." (FLOR et al. 2015, p. 163).

Nessa perspectiva, as ações desenvolvidas na educação tornam-se exclusivas, sendo assim, é necessário rever tais concepções para que não perdure o contexto apresentado por Oliveira (2013, p. 982), em que "a comunidade acadêmica e a cultura universitária adentram a uma zona de conforto na qual não se percebe a presença do diferente e, portanto, não há o reconhecimento do desafio a ser enfrentado e superado".

Os desafios são inúmeros, segundo aponta Oliveira (2013) em sua pesquisa. Os participantes, cegos, relatam que os professores não tem formação para lidar com os diferentes e não sabem o que fazer com os estudantes com limitações oriundas de deficiência. Evidencia-se assim, que a inclusão precisa ser compreendida pelas pessoas e a existência da legislação por si só, não é suficiente, visto que o processo deve levar a construção de um novo tipo de sociedade por meio de transformações que superam as barreiras mentais da sociedade.

Para Castro e Almeida (2014, p. 191) pode ser considerado como três grandes desafios para as instituições de ensino superior: "romper as barreiras ainda existentes, principalmente, as atitudinais; prever e prover as condições de acessibilidade (física, comunicacional e pedagógica) e criar alternativas para evitar práticas excludentes por parte dos professores". Completa Siqueira e Santana (2010, p. 135),

Embora sejam notórios os avanços em relação às ultimas décadas no que diz respeito aos direitos educacionais da pessoa com deficiência, ainda 
existe uma grande lacuna entre as diretrizes legais existentes e a efetivação do acesso e permanência dos estudantes com necessidades educativas especiais, principalmente na educação superior.

Mesmo assim, é preciso refletir sobre esse contexto da educação inclusiva, segundo Santarosa, Conforto e Basso (2012, p. 465) "o passado preso pela deficiência liberta-se no futuro, que é expresso na potencialidade de desenvolvimento que a diversidade humana conquista pela instituição de canais de comunicação e de intervenção no mundo". Constructo que se apresenta no trabalho de pesquisa desenvolvido pelos referidos autores, cujo objetivo foi superar o reducionismo das discussões sobre a organização do trabalho do Ambiente de Aprendizagem Virtual (AVA), tendo como foco a preocupação com a importância de impulsionar interações entre seres humanos e sistemas socioculturais por meio de recursos tecnológicos. Com vistas a explorar o potencial de interatividade propiciado pelo uso de tecnologias digitais e afirmar a concepção epistemológica sociointeracionista, no processo de ensino e aprendizagem.

É possível identificar que os ambientes digitais para tornarem-se acessíveis precisam desenvolver: conteúdos multimídias com animações e vídeos (FLOR et al., 2015; PIVETTA; SAITO; ULBRICHT, 2014; SANTAROSA; CONFORTO; BASSO, 2012); ter intérprete de Libras, visto que praticamente esse profissional nem sempre faz parte do quadro de professores; material didático é inadequado, plataformas e programas deveriam se utilizar mais das inovações tecnológicas existentes, porém o professores muitas vezes não possui domínio de tecnologias mais avançadas para utilizar como instrumento para contribuir no processo de ensino e aprendizagem; preconceito e falta de acessibilidade sentido quando os alunos precisam se locomover para realizar atividades presenciais (CASTRO; ALMEIDA, 2014; OLIVEIRA, 2013; SIQUEIRA; SANTANA, 2010).

Portanto, a acessibilidade digital deve ser compreendida nas atividades de planejamento e estruturação da interface do AVA, assim como dos conteúdos dos cursos (PIVETTA; SAITO; ULBRICHT, 2014).

\section{CONSIDERAÇÕES POSSÍVEIS}

A acessibilidade digital contemplada em cursos a distância na Educação Superior é amparada por legislações aplicáveis, resultados de políticas públicas, principalmente, desenvolvidas a partir de 2008.

No entanto, é possível verificar que a acessibilidade digital precisa ser compreendida como elemento que vai além das atividades e planejamentos das interfaces do AVA, pois a tecnologia deve ser entendida, enquanto instrumento facilitador do processo de ensino e aprendizagem, devendo ser utilizada, em favor das necessidades dos estudantes.

\section{REFERÊNCIAS}

BRASIL. Lei no 10.098, de 19 de dezembro de 2000. Estabelece normas gerais e critérios básicos para a promoção da acessibilidade das pessoas portadoras de deficiência ou com mobilidade reduzida, e dá outras providências. Diário Oficial da União, Brasília, DF, 20 dez. 2000. Disponível em: <http://www.planalto.gov.br/ccivil_03/LEIS/L10098.htm.>. Acesso em: 15 mai. 2016.

BRASIL. Decreto no 5.296, de 2 de dezembro de 2004. Regulamenta as Leis no 10.048 , de 8 de novembro de 2000, que dá prioridade de atendimento às pessoas que especifica, e 10.098, de 19 de dezembro de 2000, que estabelece normas gerais e critérios básicos para a promoção da acessibilidade das pessoas portadoras de deficiência ou com mobilidade reduzida, e dá outras providências. Diário Oficial da União, Brasília, DF, 03 dez. 2004. Disponível em: 
<http://www.planalto.gov.br/ccivil_03/_ato2004-2006/2004/decreto/d5296.htm>. Acesso em: 15 mai. 2016.

BRASIL. Ministério da Educação. Política Nacional de Educação Especial na Perspectiva da Educação Inclusiva. Documento elaborado pelo Grupo de Trabalho nomeado pela Portaria no 555/2007, prorrogada pela Portaria no 948/2007, entregue ao Ministro da Educação em 07 de janeiro de 2008. Disponível em: <http://portal.mec.gov.br/arquivos/pdf/politicaeducespecial.pdf>. Acesso em: 12 maio 2016.

BRASIL. Decreto $n^{\circ}$ 7.611, de 17 de novembro de 2011. Dispõe sobre a educação especial, o atendimento educacional especializado e dá outras providências. Diário Oficial da União, Brasília, DF, 18 nov. 20011. Disponível em: <http://www.planalto.gov.br/ccivil_03/_ato20112014/2011/decreto/d7611.htm>. Acesso em: 26 fev. 2016.

BRASIL. Lei no 13.146, de 6 de julho de 2015. Institui a Lei Brasileira de Inclusão da Pessoa com Deficiência (Estatuto da Pessoa com Deficiência). Diário Oficial da União, Brasília, DF, 07 jul. 2015. Disponível em: <http://www.planalto.gov.br/ccivil_03/_Ato20152018/2015/Lei/L13146.htm\#art112>. Acesso em: 20 mai. 2016.

CASTRO, S. F. de; ALMEIDA, M. A. Ingresso e permanência de estudantes com deficiência em universidades públicas brasileiras. Revista Brasileira de Educação Especial, Marília, v. 20, n. 2, p. 179-194, jun., 2014. Disponível em: $<$ http://www.scielo.br/scielo.php?script=sci_arttext\&pid=S141365382014000200003\&lng=en\&nrm=iso>. Acesso em: 12 nov. 2015.

FLOR, C. da S. et al. Acessibilidade do Moodle para surdos: abordagem dos discursos de surdos e ouvintes. Transinformação, Campinas, v. 27, n. 2, p. 157-163, ago., 2015. Disponível em: <http://www.scielo.br/scielo.php?script=sci_arttext\&pid=S010337862015000200157\&lng=en\&nrm=iso >. Acesso em: 12 nov. 2015.

INSTITUTO DO PATRIMÔNIO HISTÓRICO E ARTÍSTICO NACIONAL (IPHAN). Instrução Normativa no 1 , de 15 de novembro de 2003. Dispõe sobre a acessibilidade aos bens culturais imóveis acautelados em nível federal, e outras categorias, conforme especifica. Disponível em: <http://portal.iphan.gov.br/uploads/legislacao/Instrucao_Normativa_n_1_de_25_de_novembro_ de_2003.pdf>. Acesso em: 20 mai. 2016.

MANTOAN, M. T. E. Diferencia para incluir: a educação especial na perspectiva da educação inclusiva. Diversa educação inclusiva na prática, out., 2011. Disponível em:

<http://www.diversa.org.br/uploads/arquivos/artigos/artigo_mariateresamantoan_outubro.pdf>. Acesso em: 29 jun. 2016.

MOURA, M. L. S.; FERREIRA, M. C.; PAINE, P. A. Manual de elaboração de projetos de pesquisa. Rio de Janeiro: EDUERJ, 1998.

OLIVEIRA, C. B. de. Jovens deficientes na universidade: experiências de acessibilidade?. Revista Brasileira de Educação, Rio de Janeiro, v. 18, n. 55, p. 961-984, dez., 2013. Disponível em: $<$ http://www.scielo.br/scielo.php?script=sci_arttext\&pid=S1413-

24782013000400009\&Ing=en\&nrm=iso>. Acesso em: 12 nov. 2015. 
PIVETTA, E. M.; SAITO, D. S.; ULBRICHT, V. R. Surdos e acessibilidade: análise de um ambiente virtual de ensino e aprendizagem. Revista Brasileira de Educação Especial, Marília, v. 20, n. 1, p. 147-162, mar., 2014. Disponível em:

$<$ http://www.scielo.br/scielo.php?script=sci_arttext\&pid=S141365382014000100011\&lng=en\&nrm=iso>. Acesso em: 12 nov. 2015.

SANTAROSA, L. M. C.; CONFORTO, D.; BASSO, L. de O. Eduquito: ferramentas de autoria e de colaboração acessíveis na perspectiva da web 2.0. Revista Brasileira de Educação, Marília, v. 18, n. 3, p. 449-468, set., 2012. Disponível em <http://www.scielo.br/scielo.php?script=sci_arttext\&pid=S141365382012000300007\&lng=pt\&nrm=iso $>$. acessos em 13 mar. 2016. http://dx.doi.org/10.1590/S1413-65382012000300007.

SIQUEIRA, I. M.; SANTANA, C. da S. Propostas de acessibilidade para a inclusão de pessoas com deficiências no ensino superior. Revista Brasileira de Educação Especial, Marília, v. 16, n. 1, p. 127136, abr., 2010. Disponível em: <http://www.scielo.br/scielo.php?script=sci_arttext\&pid=S141365382010000100010\&lng=en\&nrm=iso>. Acesso em: 12 nov. 2015. 